\title{
A FACE QUALIFICADA-ESPECIALIZADA DO TRABALHO IMIGRANTE NO BRASIL: temporalidade e flexibilidade
}

\author{
Patrícia Villen *
}

\begin{abstract}
O objeto deste artigo é a face qualificada-especializada do trabalho imigrante, relacionada com o circuito legalizado da imigração. Examina-se a bibliografia e os diferentes tratamentos teóricos do tema, enfatizando a pertinência do prisma do "mercado global dos recursos humanos qualificados". A manifestação desses fluxos no Brasil (2007-2014) é analisada a partir das estatísticas do Ministério da Saúde e do Ministério do Trabalho e Emprego sobre o regime de visto, a composição de sexo e de nacionalidade. Uma seção é dedicada aos "marítimos globais" e aos médicos cubanos, por representarem um caso emblemático das novas bases sócio-históricas de desenvolvimento do fenômeno da imigração no país. Por fim, será feito um balanço sobre a ligação desses fluxos com movimentos de precarização do trabalho, em particular no que se refere à temporalidade e à flexibilidade.
\end{abstract}

Palavras-chave: Trabalho imigrante. Temporalidade. Flexibilidade. Marítimos globais. Mais Médicos. Brasil. Mercado de trabalho.

O início do século XXI é caracterizado por um cenário mundial inteiramente tocado pelos movimentos migratórios internacionais, compostos por fluxos SUL-NORTE (predominantemente), SUL-SUL e LESTE-OESTE (em particular na Europa). Há também fluxos internos ao NORTE, hoje bastante vivos no contexto europeu, em função da crise econômica. Os fluxos SUL-SUL atualmente não têm o peso daqueles SUL-NORTE, porém estão em contínuo crescimento, em particular para a população de refugiados e deslocados forçados. Muitos desses fluxos, na verdade, têm o SUL como destino em razão da proximidade geográfica ou mesmo como alternativa de passagem para, eventualmente, possibilitarem a meta mais almejada de um dia poder entrar no NORTE, onde os salários (diretos e indiretos) costumam ser em média mais altos. ${ }^{1}$

\footnotetext{
* Universidade Federal de Uberlânida. Instituto de Ciências Sociais.

Campus Santa Mônica - Bloco 1H Sala 20. Av. João Naves de Âvila, 2121. Cep: 38400-902. Santa Mônica - Uberlândia - Minas Gerais - Brasil. villenpatricia@gmail.com ${ }^{1}$ No ano de 2013, as estimativas da Organização das Nações Unidas indicavam a presença de 232 milhões de migrantes internacionais no mundo (cerca de $3 \%$ da população mundial), dos quais $48 \%$ eram mulheres e $74 \%$ estavam em idade ativa (20-64 anos). Mais da metade desses migrantes, quase 136 milhões (o que corresponde
}

Diversos estudos sinalizam a intensificação desses fluxos, a diversificação das nacionalidades envolvidas e, notadamente, sua extensão global de manifestação. ${ }^{2}$ Dentro desse complexo quadro, que envolve diferentes modalidades migratórias - refúgio, via circuito indocumentado, por motivo de estudo, casamento, turismo, trabalho, etc. -, este estudo focará a face qualificada-especializada do trabalho a 59\% do total), viviam nos países centrais. A população de refugiados também compõe esse quadro, cerca de 17 milhões de pessoas. Ao contrário dos demais migrantes internacionais, $87 \%$ dos refugiados se encontravam em países periféricos.

2 A literatura sobre o tema é ampla e muito antiga. Hoje, em razão das dimensões que o fenômeno adquire em escala global, esse tema é contemplado pelas diferentes áreas de conhecimento dos mais diversos países. Para consultar perspectivas críticas que destacam o caráter estrutural, internacionalmente interligado e sistêmico dos movimentos migratórios no sistema capitalista e sua importância para a configuração da globalização, ver Sassen $(1988,2014)$, Basso (2003), Mackay (2008) e Potts (1990). Para a análise das diferentes questões implicadas nos movimentos migratórios internacionais e seus desdobramentos nas sociedades, em particular no que se refere ao fenômeno do racismo e à organização dos trabalhadores imigrantes, ver Basso, 2010 e Chacon e Davis, 2006. Para um panorama das linhas gerais de interpretação desse fenômeno na atualidade e a literatura especializada nas diferentes dimensões do fenômeno, ver Fiddian-Quasmiyeh et al. 2014 e Mazzella, 2014. Não poderia deixar de mencionar um rico campo de estudos sobre as migrações internas ao Brasil, que certamente representa uma importante base analítica de interlocução para analisar a relação do trabalho com o fenômeno da imigração internacional no país. 
imigrante. Essa categoria não se refere à qualificação-especialização do imigrante, pensado individualmente, mas às portas de entrada institucionalmente legalizadas da imigração por motivo de trabalho e de sua ligação com o funcionamento do mercado de trabalho. ${ }^{3} \mathrm{Na}$ contracorrente da via indocumentada, entendida como forma de migrar imposta, na atualidade, à maior parte dos imigrantes e refugiados -, esses fluxos são os únicos que conseguem entrar pelo ultrasseletivo e burocrático circuito legalizado da imigração por motivo de trabalho.

Um elemento importante para se entender a especificidade desses fluxos é o posicionamento dos Estados-nação, ao considerá-los como reflexos naturais do funcionamento do presente estágio da economia e da livre circulação de capitais (Sassen, 2011). Os governos participam e encorajam o chamado "mercado global das competências ou dos recursos humanos" (Pizzarro, 2005) para setores específicos da indústria, serviços e finanças, no âmbito privado e público, mesmo de forma reticente em relação à permanência desses imigrantes - ou seja, abrindo as portas temporariamente (Dreher, 2007; Martin, 2006; Ruiz, 2011).

Por esse motivo, segundo esclarece o estudioso do fenômeno imigratório na Suíça, Lopreno (2015), a abordagem de pesquisas e políticas públicas sobre essa modalidade de A migração recebe atualmente a atenção de cálํㅗ culos milimétricos para precisar o chamado “capital humano” funcional a determinados . setores estratégicos da economia, especialis mente o de serviços.

o. trado, esses fluxos ganharam importância cres- cente no Brasil - não só em números, mas tamì bém na velocidade das entradas e saídas, nas $\therefore$ diferentes categorias profissionais, nacionalidades e setores econômicos implicados -, sendo

${ }^{3}$ Ademais, a noção de qualificação-especialização exige uma problematização pela sociologia do trabalho e, no que se refere aos movimentos migratórios internacionais, nem sempre há uma correspondência entre a qualificação-especialização do imigrante e sua inserção em setores altos ou baixos do mercado de trabalho. Para o tratamento mais aprofundado do tema, consultar Villen (2015). bastante nítida sua presença nas estatísticas oficiais. Não obstante, há um vazio quase completo de estudos sobre o tema, ${ }^{4}$ em particular se considerada a sociologia do trabalho. Até o momento, além dos estudos da área da demografia, que já faziam, desde a década de 2000, o mapeamento da presença desse perfil qualificado-especializado da imigração no Brasil, foram produzidas análises apenas com o propósito de discutir a necessidade da aplicação de políticas públicas para atração desses profissionais. ${ }^{5}$

Não se atentou, no entanto, para a investigação sobre a razão da manifestação desses fluxos que compóem o quadro geral do fenômeno imigratório na atualidade, das questões de fundo implicadas e das causas que levam à emigração essas categorias geralmente pensadas como "protegidas" de movimentos gerais de precarização do trabalho - como o desemprego, o rebaixamento de salários, de direitos e das condições de trabalho.

Como forma de contribuir para o preenchimento dessa lacuna, o presente estudo discute a presença desses fluxos no Brasil, levando em consideração as questões supramencionadas e suas imbricações com o funcionamento do mercado de trabalho. O período privilegiado é o de 2007-2014, tendo em vista que ele permite entender dinâmicas do fenômeno dentro do contexto de crise, desemprego e recrudescimento das políticas imigratórias nos países centrais, enquanto, no Brasil, havia um aquecimento do mercado de trabalho. Esse período contrasta com as duas décadas precedentes, porém não exclui, 4 Tal constatação compõe um quadro mais geral de silên-
cio, bastante difuso nas diferentes áreas acadêmicas, sobre
a manifestação do fenômeno da imigração no Brasil duran-
te a segunda metade do século XX, com exceção de alguns
centros de pesquisa como o Observatório das Migrações
em São Paulo (NEPO-UNICAMP). Depois de 2010, com o
aumento dos fluxos de entrada no Brasil, principalmente
de haitianos, ao contrário, é sintomático o aparecimento
de estudos sobre o tema nas diferentes áreas.
5 Os estudos de Mestrado de Coentro (2011) e Momo
(2014) abordaram o tema com base na idéia diretriz dos
fatores produtivos benéficos implicados na entrada desses
fluxos. Não por acaso, os Estados Unidos - atualmente o
principal país de destino dessa modalidade de imigração
- são utilizados como exemplo, nos dois estudos, do que
poderia ser considerado o suprassumo de uma política
bem sucedida de atração desses profissionais, na qual as
políticas públicas brasileiras deveriam se espelhar. 
é claro, suas profundas contradições, que têm sido amplamente documentadas pela sociologia do trabalho mais crítica (Antunes, 2014; Antunes; Druck, 2014; Braga, 2012; Krein, 2013b).

Com esse fim, este estudo examina, primeiramente, a bibliografia e os diferentes tratamentos teóricos do tema, enfatizando a pertinência do prisma do "mercado global dos recursos humanos qualificados”. Em seguida, a manifestação desses fluxos no Brasil (20072014) será analisada a partir das estatísticas do Ministério da Saúde (MS) e do Ministério do Trabalho e Emprego (MET), sobre o regime de visto, a composição por sexo e por nacionalidade. Adicionalmente, uma seção é dedicada aos "marítimos globais" e aos médicos cubanos, por representarem casos emblemáticos das novas bases sócio-históricas de desenvolvimento do fenômeno da imigração no país. Por fim, será feito um balanço sobre a ligação desses fluxos com movimentos de precarização do trabalho, em particular no que se refere à temporalidade e à flexibilidade.

\section{O MERCADO GLOBAL DOS "RECUR- SOS HUMANOS QUALIFICADOS”}

Decerto, a migração internacional (seja de curta, seja de longa duração) - na qual estão implicadas relações culturais, linguísticas, a dimensão política, sociológica e psicológica - oferece um substrato de pesquisa com questões complexas, que vão além da dimensão do trabalho. Nesse sentido, entende-se que as particularidades dos contextos de emigração e imigração, em conjunto com a própria complexidade das questões envolvidas no fenômeno - de natureza objetiva e subjetiva - definam a necessidade de múltiplos ângulos, descritivos e interpretativos, de suas dinâmicas.

Mais especificamente, considera-se importante a crítica do sociólogo Basso (2003), no que se refere a interpretações do fenômeno migratório internacional na atualidade que não se questionam sobre o que chama de "nexo causa-efeito”. Disso decorrem, em sua opinião, teorias e mesmo a visão de instituições sobre o tema, nas quais as diversas manifestações dos movimentos internacionais de populações aparecem como "causas sem causa", como se existissem "em si", de forma "desligada" entre si e, principalmente, "separadas" do funcionamento do mercado mundial e do mercado de trabalho na era da mundialização financeira.

Além disso, há um equívoco muito presente na atualidade dos estudos sobre migração, o de considerar a perspectiva que ilumina sua ligação com o funcionamento do mercado de trabalho como excludente da dimensão subjetiva e dos fatores de transformação inerentes à ação dos próprios imigrantes. Tal crítica geralmente acompanha uma perspectiva que parte ou acaba, inevitavelmente, assumindo o indivíduo ou a decisão individual ${ }^{6}$ como categoria explicativa das causas das migrações, consequentemente, do potencial de transformação a elas inerente.

Para além das possíveis "escolhas" internacionalizadas dos sujeitos que migram, a intensificação da mobilidade internacional da força trabalho com perfil qualificado-especializado é difícil de ser compreendida como fenômeno social se colocada fora da relação de assalariamento e do atual grau de internacionalização dos processos produtivos e financeiros que acompanham, por sua vez, um regime legal da imigração a partir de aberturas e barreiras seletivas.

Autores como Aragonés e Salgado (2011) e Sassen (2014) destacam a ligação da face qualificada-especializada do trabalho imigrante na atualidade com as novas exigências da reestruturação produtiva e seus padrões tecnológicos, bem como com a aguda manifestação do desemprego estrutural no contexto de crise eclodida em 2007 - que se prolonga nos países

${ }^{6}$ Como exemplo, temos a ideia naturalizada pela expressão "nômades globais" - defendida por Jim Mattewan (2012) - para falar de pessoas que circulam internacionalmente devido a uma escolha puramente individual e livre. Seu estudo, Os novos nômades globais, representa uma interpretação bastante difundida do fenômeno - mesmo de correntes nas Ciências Sociais - que apresenta com entusiasmo o que chama de "nova força de trabalho com mobilidade mundial". 
centrais e atualmente se propaga e se intensifica naqueles periféricos. No mesmo sentido, é inegável sua ligação com o avanço das formas de flexibilização do trabalho (Antunes, 2009; Krein, 2013a; Lima, 2013), que geram insegurança e incerteza ou mesmo a necessidade de migrar internacionalmente.

Conforme destaca Huws (2009, p. 56), "onde houver um mercado global para especializações, as escolhas dos empregadores em realocar ou não, é espelhada na decisão dos trabalhadores de imigrar ou não". A autora esclarece que os trabalhadores estão submetidos não só à escolha dos empregadores, mas também dos Estados: "tanto os Estados Unidos quanto a maior parte dos países europeus recentemente facilitaram seus procedimentos de imigração para tornar acessíveis os green cards para engenheiros de software com qualificações" (Huws, 2009, p. 56). Nessa mesma linha de raciocínio, Lopreno (2015) ressalta que, apesar da etiqueta favorável que enfatiza o diferencial da qualificação, com particular alusão à idéia da importação de "cérebros" o brain drain (drenagem de cérebros), o brain gain (ganho de cérebros), o brain circulation (circulação de cérebros) -, o trabalho desses imigrantes não deixa de ser alvo de mercantilização pelas empresas e Estados, interessados em saber quanto perdem em competitividade A quando esses migrantes deixam seu território N e quanto ganham quando os recebem.

De fato, estudos das diferentes áreas têm evidenciado como a alta demanda desses fluxos, nos países centrais, representa um elemento vital dessas economias para a manutenção da produtividade e da concorrência em escala mundial, a redução dos custos e direitos laborais e a geração de novos conhecimentos (Aragonés; Salgado, 2011). Além disso, o recebimento desses fluxos também tem a função de suprir e reduzir os custos de serviços públicos, sobretudo na área da saúde e educação.

Esse tema vem sendo bastante investigado em suas diferentes variáveis nos países centrais, por representarem o principal alvo des- ses fluxos migratórios na atualidade (Kahanec, 2013; Sassen, 2011). Tais pesquisas esclarecem o contexto no qual essa modalidade específica da migração internacional começa a se manifestar, a saber, na segunda metade do século XX, intensificando-se da década de 1990 em diante.

Conforme destaca o estudioso das dinâmicas dos fluxos internacionais na América Latina, Pizzarro (2005, p. 8), a expressão "fuga de cérebros", geralmente evocada para discutir essa modalidade de migração, foi pela primeira vez utilizada por pesquisas realizadas nos anos 1950 para tratar da emigração de médicos ingleses para os Estados Unidos, sendo depois aplicada a diferentes contextos, em particular dos países periféricos, principais territórios de produção dos movimentos de emigração da segunda metade do século XX até hoje. O autor ainda esclarece que o debate científico focou principalmente o impacto desse tipo de emigração para os países periféricos, ganhando força nas décadas de 1960 e 1970, sendo renovado nos anos 1990, durante o auge da indústria informática.

Ainda segundo o autor, o peso crescente desses fluxos se refletiu no Acordo Geral de Comércio de Serviços, da Organização Mundial do Comércio (OMC), que regulamentou, em 1995, a formação de um "mercado global de recursos humanos qualificados" para a prestação de serviços, sendo operacionalizado pelo regime temporário de residência no país de destino. Conforme destaca, o acordo "prevê a mobilidade de pessoas condicionada à prestação de serviços, mas não se aplica à inserção no mercado de trabalho, nem a direitos de cidadania e residência” (Pizarro, 2005, p. 20).

Quanto à América Latina, Pizzarro (2005, p. 12) esclarece que, desde, pelo menos, a década de 1960, há o registro de "emigração e imigração de recursos humanos qualificados, ainda que a emigração para fora da região tenha sido o traço mais chamativo em intensidade, tendências e impactos". Em decorrência, a maior parte dos estudos sobre esse tema, na região, focalizou o ponto de vista de um continente emissor de emigrantes com esse perfil (Pellegrino, 2001, 2010). 
Não obstante o campo de pesquisa que procura destacar os fatores positivos de uma organização internacionalmente móvel dessa força de trabalho envolvendo diferentes países e culturas (Nedelcu, 2004), ${ }^{7}$ os elementos contraditórios do imperativo da mobilidade no funcionamento internacionalizado do mercado de trabalho também têm sido apontados por uma ampla literatura, tanto antiga, quanto atual.

Parte desses estudos se concentra nas relações hierárquicas entre os países implicados, nas assimetrias de funcionamento dos mercados de trabalho nacionais, nos regimes seletivos e restritivos da mobilidade desses imigrantes e nos impactos socioeconômicos para os países periféricos dessa emigração (Pellegrino, 2001; Pizarro, 2005; Portes, 2008). Outra parte desses estudos investiga os fatores de precarização envolvidos nessa organização internacionalmente móvel de força de trabalho.

Esses últimos mostram como a oportunidade de emprego ou de contratos de trabalho mais estáveis tem a mobilidade internacional como contrapartida, fator que nem sempre acompanha vantagens em relação a salários, jornadas, condições de trabalhos (se considerados os parâmetros dos nacionais que ocupam os mesmos postos), além dos condicionantes burocráticos e, sobretudo, a temporalidade, como já indicado, elemento basilar do atual regime de contratação internacional de força de trabalho dentro do circuito legalizado de migração (Stasiulis, 2008), que não deixa de expressar uma dimensão da flexibilidade do trabalho sob o "império do curto prazo" (Krein, 2013a, p. 23) no funcionamento do capitalismo na era da mundialização financeira.

Nos Estados Unidos, por exemplo, há autores como Rafael Alarcón (2000) que se referem aos profissionais contratados pela in-

7 Tais marcos interpretativos se fundamentam, por exemplo, nas remessas, consideradas como fator de desenvolvimento e nas vantagens de produtividade e concorrência para o país receptor. Há estudos que enfatizam os ganhos por parte do imigrante, com relação à experiência imigratória, aos aspectos identitários, de intercâmbio cultural e linguístico. Por fim, há interpretações que assumem a mobilidade internacional como modus vivendi no atual contexto, a partir da escolha dos indivíduos. dústria informática do Vale do Silício como cerebreros ou tecnobraceros, com o fim de evidenciar alguns traços da precarização desse trabalho por meio do recrutamento internacional. Vê-se, portanto, que uma semântica que remete ao sistema de importação de mexicanos utilizado nesse país, desde a metade do século $\mathrm{XX}$, originalmente para suprir a demanda de trabalho na agricultura, está sendo utilizada por analogia para explicar fatores de precarização do trabalho relacionado a esses fluxos com perfil qualificado-especializado.

Também para Aragonés e Salgado (2011), trata-se de um sistema eficiente de fornecimento de trabalho flexível, principalmente de diplomados em idade ativa, estudantes ou jovens recém-formados no ensino superior, uma vez que propicia uma rápida contratação do profissional já formado e também uma eventual demissão - muitas vezes acompanhada de expulsão do país, caso sua força de trabalho se torne excedente e seu visto não seja renovado -, sem que o país receptor tenha investido na sua formação ou tenha de desembolsar gastos para sua permanência (aposentadoria, por exemplo).

Diante do exposto, a perspectiva de investigação adotada pelo presente estudo leva em consideração o "mercado global dos recursos humanos qualificados" - que abrange o tema mais amplo do recrutamento internacional de força de trabalho com perfil qualificado e (ou) especializado e sua relação com movimentos da precarização do trabalho - para entender a manifestação desse fenômeno no Brasil. A seguir, será feita a exposição e a análise das principais tendências da última década com relação a esses fluxos.

\section{A FACE QUALIFICADA-ESPECIA- LIZADA DO TRABALHO IMIGRAN- TE NO BRASIL}

O desenho institucional da imigração "bem-vinda" no Brasil indica a mesma tendência apontada pelos estudos anteriormente citados 
sobre o aumento da mobilidade internacional da força de trabalho com perfil qualificado-especializado (Baeninger et al., 2010), ${ }^{8}$ embora esses fluxos representem uma parcela reduzida do quadro mais complexo (e, em grande parte ,indocumentado) do fenômeno da imigração no país, não revelado pelas estatísticas oficiais (Villen, 2015). ${ }^{9}$

A Tabela 1 não deixa dúvida sobre a significativa mudança no patamar de autorizações de trabalho concedidas a estrangeiros de 2007

Tabela 1 - Autorizaçóes de trabalho concedidas a estrangeiros, Brasil (1993 a 2014)

\begin{tabular}{c|c|c|c}
\hline Ano & $\mathbf{N}^{\mathbf{o}}$ de pessoas & Ano & $\mathbf{N}^{\mathbf{o}}$ de pessoas \\
\hline 1993 & 5.376 & 2004 & 20.315 \\
1994 & 4.236 & 2005 & 24.158 \\
1995 & 3.792 & 2006 & 25.440 \\
1996 & 4.002 & 2007 & 29.488 \\
1997 & 7.090 & 2008 & 43.993 \\
1998 & 14.110 & 2009 & 42.914 \\
1999 & 12.709 & 2010 & 55.471 \\
2000 & 14.741 & 2011 & 69.077 \\
2001 & 15.903 & 2012 & 67.220 \\
2002 & 18.062 & 2013 & 62.387 \\
2003 & 17.389 & 2014 & 46.740 \\
\hline
\end{tabular}

Fonte: Ministério do Trabalho, Secretaria de Relaçóes do Trabalho - Coordenação Geral de Imigração.

${ }^{8}$ Conforme destaca o estudo de Baeninger, o circuito legalizado da imigração por motivo de trabalho apresenta um nível alto de escolaridade, sendo a maioria diplomada em Universidades ou em entidades equivalentes. Essa mesma constatação pode ser verificada nas estatísticas referentes às autorizaçốes de trabalho concedidas a estrangeiros no período de 2007-2014(consultar Villen, 2015).

今 ${ }^{9}$ Para o detalhamento desses números oficiais e para a จ problematização de como não contemplam ou subesti. mam uma grande parcela de imigrantes indocumentados, provenientes de países periféricos, que são invisibilizados,

ver Villen, 2015. Se considerada a média de $10,8 \%$ da poฮี pulação estrangeira nos países centrais, percebe-se que a porcentagem estimada oficialmente da população estran10 geira no Brasil (2013), de aproximadamente 0,5\%, é muito ळె inferior (UN, 2013). Nos últimos cinco anos, os fluxos de entrada de haitianos foram os mais importantes. Segundo

2 algumas estimativas, que consideram também os indocu-

s mentados, em 2015 havia 50.000 haitianos residindo no

\& Brasil, com ingressos que começaram a ganhar volume a

- partir de 2011 (ver Baeninger et al., 2016). No entanto, há

के fluxos de entrada de muitas outras nacionalidades, prin-

$>$ cipalmente de proveniência de países periféricos, nota-

î damente aqueles fronteiriços com o Brasil, mas também

de outros continentes (africano e asiático). Além disso,

2 segundo o CONARE (2016), havia, no Brasil, um estoque

क de oito mil refugiados no ano de 2015 . As principais nacio-

nalidades são: sírios, angolanos, colombianos, congoleses

I e palestinos. Já o estoque de solicitantes de refúgio - que

ơ ainda aguardam o processo formal de reconhecimento do

- estatuto de refugiado - é muito maior (com mais 20.000

solicitantes nesse mesmo ano), sendo principalmente

composto por haitianos, senegaleses, sírios, bengaleses,

ङ angolanos, congoleses, ganeses, libaneses e venezuelanos. para 2008, quando salta de 29 mil para quase 44 mil, crescendo ainda no período seguinte, quando supera as 60 mil autorizações anuais.

Essa modalidade de imigração ocorre em geral, mas não somente, por circuitos legalizados e de entrada facilitada para atuação em diversos setores de peso da economia nacional, sendo representada oficialmente como um produto da forte seletividade do mercado de trabalho, bem como das diretrizes da política nacional de desenvolvimento, principalmente para suprir a "falta", no país, de profissionais qualificados para atuação em setores específicos. ${ }^{10}$

Há um nítido desequilíbrio na composição por sexo nesses fluxos, o que pode ser verificado em todas as categorias, confirmando as tendências já analisadas pela literatura internacional do "impacto de gênero" nessa mobilidade (Hirata, 2009; Morokvasic, 2011; Oliver, 2009; Preston e D'Addario, 2008; Roulleau-Berger, 2010). ${ }^{11}$ Como mostra a Tabela 2 , nos últimos quatro anos, o percentual de auto-

Tabela 2 - Relação de autorizações de trabalho concedidas a estrangeiros por sexo (2006 a 2014)

\begin{tabular}{c|c|c|c}
\hline \multirow{2}{*}{ Ano } & \multicolumn{2}{|c|}{ Gênero } & \multirow{2}{*}{ Total geral } \\
\cline { 2 - 3 } & Masculino & Feminino & \\
\hline 2006 & 23.608 & 1.832 & 25.440 \\
2007 & 26.471 & 3.017 & 29.488 \\
2008 & 39.551 & 4.442 & 43.993 \\
2009 & 39.119 & 3.795 & 42.914 \\
2010 & 35.493 & 3.564 & 39.057 \\
2011 & 62.807 & 6.990 & 69.077 \\
2012 & 60.807 & 6.413 & 67.220 \\
2013 & 55.728 & 6.659 & 62.387 \\
2014 & 41.602 & 5.138 & 46.740 \\
\hline
\end{tabular}

Fonte: Ministério do Trabalho e Emprego

(Base Estatística - CNIg).

${ }^{10}$ A lei 6.815/80, que regulamenta o estatuto do estrangeiro no país, restringe a imigração a casos escolhidos (e sujeitos a uma aprovação altamente burocrática e demorada) de "mão-de-obra especializada", funcional "ao desenvolvimento do país", "em especial ao aumento da produtividade, à assimilação de tecnologia e à captação de recursos para setores específicos”. Os projetos de lei que estão sendo discutidos para substituir essa lei não modificam esse critério em relação aos fluxos de entrada no país por motivo de trabalho.

11 Tudo indica que a imigração feminina no Brasil, como no mundo, é principalmente destinada a empregos marcados pela precarização. No país, até o momento, foi direcionada mais à indústria (em particular a têxtil) que ao trabalho doméstico. 
rizações de trabalho para mulheres imigrantes ficou em torno de meros $10 \%$ do total.

Oliver (2009), referindo-se à Comunidade Europeia, destaca que os setores da economia que hoje demandam uma alta mobilidade internacional (acadêmico, científico, de negócios, manejo de tecnologia) permitem mais a circulação de homens, tanto nos países centrais, como nos periféricos. Essa constatação também é confirmada por Laurence Roulleau-Berger (2010), que afirma, a partir do estudo do caso francês, que "poucas mulheres em migração têm acesso a cargos prestigiosos", ou seja, seu estudo mostra que "a realidade complexa dos mercados de trabalho situa as mulheres em migração na margem [de seu funcionamento].” (op. cit., p. 156). Contudo, Roulleau-Berger também esclarece que tal constatação não significa que essas mulheres não estejam participando da construção de espaços econômicos transnacionais (nos seto- res da indústria, turismo, moda, arte etc.), que hoje exercem um papel central para as novas formas de acumulação (op. cit., p. 169).

Pelos dados evidenciados na Tabela 3 , também, é possível notar a presença de uma ampla gama de nacionalidades implicadas. Há, principalmente, nacionalidades dos países centrais ou daqueles com "posição intermediária" no mercado mundial (Índia, China, Coreia do Sul). As Filipinas representam uma exceção, que será tratada no item a seguir.

O estudo de Baeninger e Leoncy (2001) esclarece elementos para se entender a composição de nacionalidade desses fluxos: o investimento de capital estrangeiro e o funcionamento de empresas transnacionais no Brasil - polo que mais atrai esses profissionais, em particular, nos Estados de São Paulo e Rio de Janeiro. É preciso entender, portanto, a relação desses fluxos com a entrada de capital estrangeiro no país. Essa conexão foi analisada no

Tabela 3- Autorizações concedidas no Brasil por país de origem (2006 a 2014)

\begin{tabular}{|c|c|c|c|c|c|c|c|c|c|}
\hline País & 2006 & 2007 & 2008 & 2009 & 2010 & 2011 & 2012 & 2013 & 2014 \\
\hline EUA & 3.601 & 4.519 & 5.799 & 5.590 & 7.520 & 10.098 & 9.138 & 8.943 & 5.830 \\
\hline Filipinas & 1.542 & 2.120 & 4.825 & 4.969 & 6.530 & 7.798 & 5.179 & 5.117 & 4.486 \\
\hline Reino Unido & 2.199 & 2.474 & 3.874 & 3.496 & 3.828 & 2.500 & 4.363 & 4.089 & 3.296 \\
\hline Índia & 766 & 1.292 & 1.981 & 2.630 & 3.234 & 4.262 & 4.235 & 3.756 & 2.663 \\
\hline Itália & 1.099 & 1.382 & 1.413 & 1.395 & 2.006 & 2.421 & 2.999 & 2.688 & 2.545 \\
\hline Espanha & 655 & 878 & 1.133 & 1.104 & 1.425 & 1.844 & 1.992 & 2.677 & 2.229 \\
\hline Portugal & 477 & 550 & 679 & 708 & 757 & 1.547 & 2.171 & 2.913 & 1.921 \\
\hline França & 1.210 & 1.377 & 1.613 & 1.908 & 1.597 & 2.166 & 2.369 & 2.265 & 1.785 \\
\hline China & 717 & 1.078 & 2.422 & 1.405 & 2.154 & 2.639 & 3.082 & 2.354 & 1.561 \\
\hline Alemanha & 1.553 & 1.292 & 1.815 & 1.454 & 2.873 & 3.162 & 3.589 & 2.900 & 1.437 \\
\hline Coréia do Sul & 253 & 126 & 203 & 214 & 897 & 1.440 & 2.311 & 1.461 & 1.429 \\
\hline Japão & 1.278 & 1.244 & 1.804 & 1.237 & 1.761 & 2.260 & 2.316 & 2.024 & 1.352 \\
\hline Indonésia & 126 & 267 & 1.356 & 1.700 & 1.819 & 2.682 & 2.306 & 2.253 & 1.130 \\
\hline Outros & 9.855 & 10.763 & 14.830 & 14.863 & 19.070 & 24.258 & 21.170 & 18.947 & 15.076 \\
\hline Total & 25.331 & 29.362 & 43.747 & 42.673 & 55.471 & 69.077 & 67.220 & 62.387 & 46.740 \\
\hline
\end{tabular}


estudo de Sassen (1988), The mobility of labor and capital, o qual explicita que a mobilidade do capital cria condições - como um "fator indutor" - da mobilidade da força de trabalho. Nesse sentido, a autora aconselha olhar para o significativo movimento de deslocamento de empresas transnacionais e demais investimentos de capitais estrangeiros nos países periféricos, intensificados na segunda metade do século XX e presentes até hoje, para se compreender as configurações dos movimentos internacionais de força de trabalho na contemporaneidade. ${ }^{12}$

A mesma tendência, já indicada (Pizzarro, 2005), de uma gestão de caráter temporário aplicada a esses fluxos, se revela nos dados referentes à década de 2000, com um nítido aumento de vistos com prazo determinado (para estrangeiros com ou sem contrato de trabalho), em detrimento dos vistos permanentes, destinados em grande parte a investidores ou executivos de transnacionais que atuam no Brasil (Baeninger et al., 2010). Na Tabela 4, relativa às entradas por motivo de trabalho dentro do circuito legalizado, está estampado esse tratamento temporário da imigração a partir do ideal do trabalhador hóspede, o gastarbeiter, modelo aplicado principalmente pelas políticas imigratórias na Alemanha, no passado e no presente (Kammerer, 1976). Trata-se de um trabalho imigrante que tem o tempo de sua permanência no país de destino ditado pelas necessidades econômicas do mercado. Essa tabela demonstra como esse tempo de permanência no Brasil se revela bastante curto, ou seja, é indicativo da velocidade de entradas e saídas desses fluxos, já que a maior parte das autorizações tem duração de somente três meses.

A "provisoriedade" implícita no regime aplicado a essa força de trabalho internacionalmente móvel, ou seja, no visto temporário, comunica-se com os diferentes tipos de contratos temporários, ao revelar a organização flexível do trabalho imperante na atualidade, com diferentes custos - objetivos e subjetivos - para o trabalhador, e suas condições gerais de salários e direitos (Antunes, 2009; Gallino, 2011; Lima, 2013). Trata-se, portanto, de uma contratação internacionalizada por demanda e just in time do regime de acumulação flexível (Harvey, 1992). No Brasil, essa contratação temporária era, antes, um recurso utilizado, em particular

Tabela 4 - Relação de autorizações de trabalho concedidas a estrangeiros, por ano, síntese por prazo de concessão dos vistos temporários (2006 a 2014)

\begin{tabular}{|c|c|c|c|c|c|}
\hline $\begin{array}{l}\text { Síntese por prazo } \\
\text { de concessão } \\
\text { (temporários) }\end{array}$ & Até 90 dias & Até 1 ano & $\begin{array}{l}\text { Até } 2 \text { anos com } \\
\text { contrato de } \\
\text { trabalho no Brasil }\end{array}$ & $\begin{array}{l}\text { Até } 2 \text { anos sem } \\
\text { contrato de } \\
\text { trabalho no Brasil }\end{array}$ & Total \\
\hline 2006 & 10.110 & 3.626 & 2.236 & 7.413 & 23.385 \\
\hline 2007 & 11.305 & 5.803 & 2.009 & 7.756 & 26.873 \\
\hline 2008 & 13.713 & 14.245 & 2.339 & 10.974 & 41.271 \\
\hline 2009 & 12.423 & 12.028 & 2.578 & 13.431 & 40.460 \\
\hline 2010 & 16.498 & 17.327 & 4.052 & 15.347 & 53.224 \\
\hline 2011 & 22.716 & 20.623 & 5.095 & 17.957 & 66.391 \\
\hline 2012 & 24.259 & 18.390 & 5.970 & 15.663 & 64.282 \\
\hline 2013 & 18.707 & 18.992 & 6.216 & 15.513 & 59.428 \\
\hline 2014 & 9.903 & 7.126 & 6.204 & 20.755 & 43.988 \\
\hline $\begin{array}{l}{ }^{12} \text { Não é um acaso h } \\
\text { século XX, a Améric } \\
\text { te pelas migraç̃̃es } i \\
\text { no da emigraçấ, qu } \\
\text { quanto nos países c } \\
\text { ropa ocidental e no } \\
\text { (2003) e Campos (20 }\end{array}$ & $\begin{array}{l}\text { tórico que, ne } \\
\text { Latina fosse r } \\
\text { ernas campo- } \\
\text { buscava saíd } \\
\text { trais, em part } \\
\text { apão. Para det } \\
\text { 9). }\end{array}$ & $\begin{array}{l}\text { egunda meta } \\
\text { ada profunda } \\
\text { ide e pelo fer } \\
\text { nto inter-regi } \\
\text { ar nos EUA, r } \\
\text { s, consultar }\end{array}$ & \multicolumn{3}{|c|}{$\begin{array}{ll}\text { o } & \text { pelas grandes empresas, para reduzir custos e } \\
\text { is } & \text { recrutar força de trabalho segundo as oscila- } \\
\text { - } & \text { ções do mercado (Krein, 2013a). Hoje, todavia, } \\
\text { tende a se disseminar, inclusive nas contrata- }\end{array}$} \\
\hline
\end{tabular}


ções em regime público pelo próprio Estado, direta ou indiretamente, via terceirização.

Além disso, é preciso considerar que a possibilidade de imigrar dentro dos circuitos legalizados para trabalhar obedece a um "modelo patronal", exatamente o que Perocco (2011) identifica como uma marca característica da organização do sistema de imigração nos países centrais, demonstrado pelo caso italiano e, em geral, pelo europeu. O autor utiliza essa expressão para ressaltar o peso do vínculo exigido institucionalmente entre visto, residência e contrato de trabalho, que acentua a dependência do trabalhador imigrante para com o seu empregador, ou seja, faz com que o prazo de validade dos direitos do primeiro, desde o pedido da permissão de entrada no país, coincida com a validade e renovação do contrato de trabalho. Sua entrada e permanência ficam, portanto, condicionadas ao poder do empregador de declarar sua utilidade para o país como força de trabalho. Não se quebra, assim, o vínculo de dependência do imigrante para com o empregador e com um processo burocrático penoso ${ }^{13} \mathrm{Na}$ prática, somente as empresas de grande porte ou de capital transnacionalizado bancam os custos dessa burocracia e conseguem a autorização de trabalho para o imigrante. Essa burocracia para a entrada e a permanência no país por motivo de trabalho, portanto, não se comunica com empregos e postos de trabalho de baixa remuneração que, em teoria, não exigem "conhecimentos específicos" - normalmente exigidos pelas leis.

Por fim, convém destacar que tal regime - burocrático, ultrasseletivo e temporário da imigração por motivo de trabalho - também pode criar como subproduto a indocumentação desses trabalhadores, em situações de demora na concessão - ou mesmo indeferimento - do visto, bem como de permanência no país após seu vencimento. Há um amplo contingente do trabalho imigrante atingido por esse fenômeno, mesmo

${ }^{13}$ Mesmo quando a empresa tem interesse em manter a contratação, o imigrante ainda precisa passar pelo segundo teste da renovação do visto ou da sua transformação em permanente. nos estratos altos do mercado de trabalho.

A indocumentação, no que se refere aos efeitos que possui nas relações laborais, não é somente um sinônimo de informalidade (Villen, 2016). No exercício de uma atividade laboral, em termos formais (de direito), tem os mesmos efeitos, mas sua substância vai além dessa esfera, pois carrega um peso a mais de condicionamentos - objetivos e subjetivos - que colocam o imigrante numa situação ainda mais vulnerável do que aquela contida no trabalho informal, com efeitos amplos também na vida social. As razões de existência do fenômeno da indocumentação se encontram essencialmente nas vantagens salariais, produtivas e de controle da força de trabalho pelo empregador e pelo próprio Estado, com possíveis consequências graves para o trabalhador imigrante, como a prisão e a deportação. ${ }^{14}$

A seguir, serão expostos elementos de novidade de casos emblemáticos para se compreender as dinâmicas de manifestação do fenômeno imigratório na atualidade do Brasil.

\section{OS CASOS EMBLEMÁTICOS DOS "MARÍTIMOS GLOBAIS" E DOS MÉDICOS CUBANOS}

A manifestação da face qualificada-especializada do trabalho imigrante no Brasil se comunica com a realidade mais ampla do aumento dos fluxos migratórios em âmbito internacional. Sassen $(2011,2014)$ forneceu pistas analíticas preciosas para se compreender a ligação dessa modalidade migratória com outros circuitos de migração em escala global, dinâmicos e multilocais, ${ }^{15}$ oferecendo elementos

${ }^{14}$ No Brasil, até o momento, essa questão ainda não foi investigada, mas parece ser bastante disseminada, até mesmo em profissões tradicionais, como a medicina. Os imigrantes provenientes de países que não possuem acordo de residência com o Mercosul ou a permissão de permanência como turistas por três meses (renováveis), como ocorre para os países da União Europeia, são os principais candidatos a essa condição de trabalho imigrante qualificado-especializado, porém efetivamente indocumentado.

15 Para uma análise mais aprofundada da sua perspectiva sobre a configuração polarizada dos fluxos migratórios internacionais na atualidade, ver Villen (2015). 
que ajudam a pensar a unidade do processo de "expulsões" que produz tais fluxos e sua ligação com o funcionamento do mercado de trabalho.

No tocante a essa modalidade do trabalho imigrante, que entra pelo circuito legalizado, há, certamente, contrastes impeditivos de qualquer generalização no que se refere à inserção desses imigrantes no mercado de trabalho brasileiro. Nessa última década, houve o aumento de entrada de assalariados de empresas transnacionais - como engenheiros, técnicos em informática, tradutores, etc. -, de professores e pesquisadores universitários, de professores de língua estrangeira, além das categorias que já se manifestavam nas décadas anteriores, por estarem diretamente relacionadas com o funcionamento de empresas transnacionais e investimentos de capitais no país. Todavia, há também elementos de novidade que ganham peso no período analisado, como as expressivas contratações nos serviços públicos de saúde e educação, ou ainda a categoria completamente silenciada de trabalhadores marítimos de proveniência asiática, que passamos a analisar a seguir, por serem casos emblemáticos da nova base sócio-histórica da imigração no Brasil.

O aumento do volume de ingresso da categoria de trabalhadores de embarcação ou plataforma estrangeira no Brasil ainda não foi investigado por pesquisas, mas sinaliza um caso సे. que merece cuidadosa atenção. Em particular, devido aos projetos de expansão do setor de ซี petróleo, que ganhou força com a descoberta in da reserva de petróleo da camada Pré-Sal (Vaळे lor Econômico, 2014) ${ }^{16}$ e está interligado com ò uma ampla cadeia produtiva e financeira, ${ }^{17}$ $\therefore$ em escala nacional e internacional. A terceiले rização, principal meio utilizado nas últimas

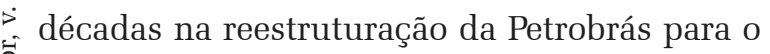
rebaixamento de custos - com consequências

${ }^{16}$ Essa descoberta foi anunciada em 2006. A reserva de petróleo do país, em 2014, era estimada em 6 bilhões de barris, passando a um patamar entre 35 e 45 bilhões de barris com as estimativas de exploração dessa camada.

${ }^{17}$ Por exemplo, o número de estaleiros passou de dois, em 2003, a dez em 2014. graves para seu grande contingente de trabalhadores contratados direta e indiretamente (Druck, 1995) - parece estar se articulando com a condição de trabalho imigrante.

Segundo Zanin (2007), sociólogo italiano e um dos maiores especialistas no tema do trabalho marítimo na atualidade, o Brasil, já no início da década de 2000, despontava como mercado "emergente" na importação dos "marítimos globais", ${ }^{18}$ em particular de origem asiática. Os dados da Tabela 5 mostram que, entre 2006 e 2013, houve aumento de ingressos dessa categoria no Brasil, de 7.405 para 15.229 pessoas.

\begin{tabular}{|c|c|}
\hline Ano & $\mathrm{N}^{\circ}$ autorizações \\
\hline 2006 & 7.405 \\
\hline 2007 & 7.756 \\
\hline 2008 & 10.974 \\
\hline 2009 & 13.371 \\
\hline 2010 & 15.207 \\
\hline 2011 & 17.738 \\
\hline 2012 & 15.554 \\
\hline 2013 & 15.229 \\
\hline $3^{\circ}$ tri 2014 & 11.797 \\
\hline
\end{tabular}

Fonte: Ministério do Trabalho e Emprego (Base Estatística - CNIg). Obs.: Para o ano de 2014, os últimos dados disponíveis são relativos Obs.: Para o ano
ao $3^{\circ}$ trimestre.

A análise do principal país de proveniência desses fluxos, nessa última década, as Filipinas, deixa bastante evidente o salto quantitativo de seu ingresso na década de 2000 com relação à de 1990. Segundo o estudo de Baeninger e Leoncy (2001), durante todo o intervalo de 1993-2000, haviam sido concedidas apenas 983 autorizações de trabalho para filipinos (considerando-se todos os tipos de visto). A Tabela 6 revela que, na década de 2010,

${ }^{18}$ Segundo Zanin as estatísticas dos marítimos globais são construídas com base em critérios diferenciados segundo as entidades fornecedoras de dados sobre essa categoria (como, por exemplo, o exercício da atividade em água internacional, o peso da embarcação e a propriedade final do trabalho na embarcação). Conforme destaca o autor, a categoria dos marítimos globais, empregados em embarcações de propriedade transnacional, corresponde hoje a $2 / 3$ dessa força de trabalho. 
por sua vez, em apenas quatro anos, foram re- (empregadoras e terceirizadas); 3) as agências gistradas mais de 13.000 autorizações para o de recrutamento especializadas; e 4) o exército trabalho de filipinos em embarcações ou plata- de trabalhadores marítimos de diferentes nacioformas estrangeiras. ${ }^{19}$ nalidades, notadamente asiáticas.

\begin{tabular}{l|r|r|r|r}
\multicolumn{5}{c}{ Tabela 6 - Profissionais estrangeiros para trabalho a bordo de } \\
embarcação ou plataforma estrangeira autorizada a \\
operar no Brasil - até dois anos -, por nacionalidade \\
(2011 a 2014)
\end{tabular}

Fonte: Ministério do Trabalho e Emprego (Base Estatística - CNIg)

Obs.: para o ano de 2014, os últimos dados disponíveis são relativos ao $3^{\circ}$ trimestre.
Segundo o autor, há uma nova divisão do trabalho permitida pelas tecnologias que, além de acompanhar a redução significativa dos números absolutos de funcionários nas embarcações, atingiu mais fortemente os cargos de oficiais (nos estratos mais altos da hierarquia do trabalho nas embarcações), historicamente preenchidos pelos brancos ocidentais, com um concomitante aumento na demanda pela força de trabalho para executar tarefas comuns nessas embarcações, que já eram, desde o passado, reservadas em maior grau aos asiáticos. Em sua opinião, essa antiga divisão do trabalho continua hoje a se reproduzir em razão dos salários mais baixos e da flexibilidade garantida pelos con-
O estudo de Zanin (2007) é crucial para o entendimento da causa de fundo da manifestação desses fluxos e sua conexão com uma rede mais ampla em nível global. Com base na análise de fontes estatísticas das agências específicas de navegação marítima e na literatura internacional sobre o tema, o autor analisa o funcionamento de uma indústria operacionalizada em rede mundial, que tem como elemento-base o recrutamento internacional de trabalhadores marítimos. Sua análise destaca os quatro pilares sobre os quais essa indústria se articula atualmente: 1) os Estados (como consumidores e organizadores do recrutamento dos trabalhadores marítimos); 2) as empresas transnacionais

${ }^{19}$ No Brasil, por enquanto, os fluxos de entrada de proveniência das Filipinas são provavelmente de homens, por serem destinados ao trabalho nas embarcações. No entanto, é bastante conhecido o massivo fluxo de mulheres filipinas que se inserem no trabalho doméstico ou de cuidado, na Europa e nos Estados Unidos, bem como aquele para o Japão, ligado à indústria do sexo ver (Falquet, 2006; Sassen, 2006). Recentemente, algumas notícias de jornais informaram a existência de mulheres filipinas que estão sendo contratadas em São Paulo, por intermediação de agências, para exercer trabalho doméstico ver (Arraes, 2015). tratos de duração mais longa de permanência nas embarcações..$^{20}$ Em suas palavras,

[...] ainda hoje, os salários médios desembolsados aos marítimos asiáticos provenientes dos principais países fornecedores dessa força de trabalho são nitidamente inferiores às médias dos salários europeus, norte-americanos e japoneses [...]. Mesmo quando os salários são equivalentes, os contratos dos trabalhadores marítimos asiáticos em embarcações estrangeiras preveem a duração da permanência nas embarcações e dedicação [ao trabalho] nitidamente mais longa, em relação aos colegas provenientes de países ricos europeus de antiga industrialização. De modo que o maior tempo distante de casa - e o stress implicado - permite aos empregadores economizarem custos com aviões para pegar e devolver os

${ }^{20}$ Isso não significa que os vistos para esses trabalhadores também sejam de longa duração, mas que o tempo de permanência nas plataformas para trabalhar, sem pisar em terra firme, é mais longo para eles. Trata-se, como especifica Zanin, de uma imposição aos trabalhadores imigrantes asiáticos que permite às empresas a economia de custos com os seus deslocamentos. É claro que esse regime diferenciado do tempo de permanência nas plataformas também implica "custos" - físicos e emocionais - para esses trabalhadores, que são obrigados a suportar uma permanência mais longa nas plataformas, trabalhando. 
marítimos no lugar de partida, antes e no final do embarque (Zanin, 2007, p. 282-283).

Por esse motivo, o recrutamento dos "marítimos globais" é, hoje, alvo de uma "verdadeira indústria de Estado" (Zanin, 2007, p. 285), pelo fato de eles se empenharem na criação das "vantagens competitivas" e estarem interessados no quanto ganham com a tributação e as remessas enviadas por esses trabalhadores. Segundo o autor, os Estados - notadamente das Filipinas, China, Índia, Indonésia, Bangladesh e Mianmar ${ }^{21}$ - se encarregam de organizar um complexo sistema de formação e certificação da habilitação para o trabalho marítimo a bordo de embarcações, de regulamentar as agências de recrutamento especializadas nessa força de trabalho, contribuindo também, com isso, para seu disciplinamento.

O estudo citado fornece diversos elementos para a compreensão da função desses Estados: impor leis e práticas que reforçam a natureza coagida desse trabalho que, pelas características específicas da situação de risco envolvida nas plataformas, fica submetido a um código de disciplina semimilitar, com proibição da representação sindical, punição pela deserção e indisciplina por meio das listas negras ${ }^{22} \mathrm{e}$ até mesmo o encarceramento, em caso de infra-

${ }^{21}$ Para compreender por que esses países são hoje os principais exportadores de trabalhadores marítimos - seguin-

^ do o conselho metodológico de Sayad (1998), ao conside-

- rar a imigração como um fenômeno inseparável da emigra-

ㄱ ção - seria necessário também analisar as condições sócio-

¿ -históricas de trabalho e de vida nesses países. Esse olhar

¿ dialético não deve ser desprezado, mas, pelo escopo deste

¿ artigo - de demonstrar a presença desse trabalho imigrante

ฮ no país e sua ligação com o funcionamento internacionali-

○ zado do mercado de trabalho -não pode ser contemplado.

L No entanto, tal perspectiva investigativa será imprescindí-

๓ vel para qualquer pesquisa sociológica que se proponha a

- debruçar-se sobre o tema e a aprofundar suas dimensões.

i. Igualmente, também se mostra necessária a realização de

$\curvearrowright$ uma pesquisa de campo que possa colher a experiência

¿ migratória, de trabalho e de vida desses imigrantes. Sabe-

○ -se que, pelo fato de esse trabalho ser altamente controlado

pelas empresas, agências e Estados, tal tarefa não será fá-

$\rightarrow$ cil, tampouco impossível.

के 22

긍 ${ }^{22}$ Blacklist é um meio de controle dos trabalhadores marí-

$\stackrel{\pi}{\geq}$ timos utilizado por alguns Estados asiáticos fornecedores

స dessa força de trabalho e pelas agências de recrutamento

- para impor puniç̃es e proibições. Essa lista é destinada

I a deixar marcado o nome do trabalhador, para que não

ک seja mais recrutado pelas agências e eventualmente seja

$\circ$ punido pelos Estados, por motivos como o da filiação $a$

sindicato, abandono das embarcações (deserção), desobe-

diência à disciplina de trabalho imposta nas embarcações,

$\circlearrowleft$ entres outros. ções, quando retornam ao país de origem.

Logo, trata-se de um trabalho que implica uma condição que, - por diversos fatores, a começar pelo isolamento geográfico sobre as águas e o confinamento nas embarcações, o tratamento jurídico, a disciplina semimilitar, a forte hierarquia na estratificação e a divisão do trabalho nas embarcações, a proibição da organização sindical, o racismo e a discriminação - equivale a estar sempre à beira da coação, daí sua denominação forçados do mar (Zanin, 2007).

Por outro lado, diferentemente do silêncio, tanto de pesquisas acadêmicas quanto da mídia, sobre a presença dos trabalhadores marítimos de origem asiática no país - não obstante o volume anual significativo dos fluxos de entrada -, a chegada dos médicos cubanos no Brasil em 2013, contratados pelo Programa Mais Médicos, gerou um "alarde" de discussões de diferentes vieses, desde posições políticas conservadoras, contrárias à importação de médicos de um país comunista, até opiniões xenófobas e racistas. Diversos fatores contextuais evidenciam, na verdade, como a discussão suscitada foi (e ainda é) demasiadamente centrada no fato de que a maioria dos médicos importados seja de nacionalidade cubana.

Para além dos posicionamentos políticos e a despeito de o sistema de saúde em Cuba ser referência mundial, a atuante campanha contra o programa Mais Médicos, no fundo, comporta também nuances racistas, com efeitos práticos contra os médicos cubanos. Muitos desses médicos sentiram na pele a exposição a xingamentos, ao descrédito em seu profissionalismo e eficiência no exercício de suas atividades e até na capacidade linguística de se comunicar com a população brasileira. Portanto, esse é um caso emblemático que evidencia claramente como o racismo pode se manifestar, mesmo nos estratos mais altos de inserção do trabalho imigrante.

Esse caso também contém elementos novos para a história da imigração do país. A presença de imigrantes (principalmente latino-americanos) nessa área do setor público já 
era uma realidade, se consideradas as últimas duas décadas, porém mais limitada em números. A título de comparação, entre os anos de 1998 e 2000, foram concedidas apenas 285 autorizações de trabalho para médicos (Baeninger e Leoncy, 2001). Nos anos mais recentes, essas autorizações atingem patamares completamente distintos. Entre os anos de 2013 e 2014, foram contratados, em regime temporário de três anos (renovável uma única vez por igual período) 12.165 médicos de nacionalidade estrangeira para atuar em 2.177 municípios espalhados pelo Brasil.

No total dos contratados, os principais representantes eram cubanos, 11.452 (6.676 mulheres e 4.776 homens), seguidos de venezuelanos, argentinos, uruguaios e bolivianos. Conforme é possível notar na Tabela 7, há mais nacionalidades periféricas implicadas, sendo a Espanha e Portugal os principais representantes de países centrais. Em seu conjunto, o

Tabela 7 - Médicos participantes do programa "Mais Médicos", por nacionalidade e sexo (2013 a 2014)

\begin{tabular}{l|r|r|r}
\hline País de origem & Mulheres & Homens & \multicolumn{1}{c}{ Total } \\
\hline Cuba & 6.676 & 4.776 & 11.452 \\
Argentina & 65 & 80 & 145 \\
Bolívia & 27 & 45 & 72 \\
Espanha & 20 & 34 & 54 \\
Colômbia & 7 & 11 & 18 \\
Haiti & 6 & 15 & 21 \\
Honduras & 9 & 6 & 15 \\
Itália & 3 & 10 & 13 \\
México & 7 & 17 & 24 \\
Portugal & 10 & 14 & 24 \\
Rep. Dominicana & 10 & 16 & 26 \\
Paraguai & 4 & 3 & 7 \\
Uruguai & 30 & 36 & 66 \\
Venezuela & 74 & 77 & 151 \\
Peru & 7 & 9 & 16 \\
El Salvador & 4 & 5 & 9 \\
Alemanha & 1 & 4 & 5 \\
Total & 6.974 & 5.191 & 12.165 \\
\hline
\end{tabular}

Fonte: Elaboração própria, com dados obtidos junto ao Ministério da Saúde. Obs.: Foram colocadas, na Tabela, apenas as nacionalidades mais representativas; por isso, o Total não representa a soma das nacionalidades expressas. programa envolve profissionais de 49 distintas nacionalidades. Na contratendência do desequilíbrio de gênero típico desse circuito do trabalho imigrante, a contratação de mulheres supera a de homens, respectivamente de 6.974 e 5.191. A Tabela 7 esclarece a composição por nacionalidade e sexo dos fluxos relacionados ao programa Mais Médicos.

Embora as particularidades do contexto nacional cubano e de seu sistema de exportação de médicos devam ser consideradas e impliquem ambivalências para se analisar esse processo de trabalho no Brasil, ${ }^{23}$ é igualmente necessária a compreensão de suas conexões com o contexto internacional. Não é por acaso que a migração internacional de profissionais da área da saúde, em particular de médicos e enfermeiras, também está aumentando em escala mundial (OIT, 2014). A intensificação do grau de internacionalização do funcionamento dos mercados de trabalho e a escassez desse serviço em diferentes países colaboram para que esse sistema ganhe amplitude em âmbito global, sendo utilizado principalmente nos países centrais (Massanet; Andrés, 2013; Wickramasekara, 2014). O caso do Reino Unido é exemplar, pois apresenta altas taxas de recrutamento internacional desses serviços, seja internamente à União Europeia (nas periferias da zona do Euro), seja externamente (nas Filipinas, por exemplo). De fato, esses milhares de médicos imigrantes que hoje atuam no Brasil revelam como esses fluxos também estão presentes no país e como o Estado brasileiro ocupa o lugar de consumidor direto da face qualificada-especializada da força de trabalho imigrante.

${ }^{23} \mathrm{O}$ recrutamento dos médicos cubanos se mostra um caso antitético da imigração internacional no Brasil contemporâneo, que está sendo aprofundado no âmbito da pesquisa de Pós-Doutorado desta pesquisadora, visando a oferecer um estudo para captar as especificidades e ambivalências dessa imigração, bem como sua ligação com tendências mais gerais do funcionamento do mercado de trabalho e a circulação internacional de força de trabalho na área dos serviços de saúde. 
No que se refere aos médicos cubanos, há um sistema peculiar - e interestatal - de recrutamento internacional dessa força de trabalho, via Estado brasileiro e cubano, com a intermediação da Organização Panamericana de Saúde (OPAS). O salário oferecido pela jornada de 40 horas semanais, em 2014, era de $\mathrm{R} \$ 10.000,00$, mais a ajuda de custo, a cargo dos Municípios, para despesas de aluguel e alimentação (que podia variar de $\mathrm{R} \$ 1.500$ a $\mathrm{R} \$ 3.000$ ) e o pagamento de passagens. Esses médicos retêm de 15 a $20 \%$ do salário - sendo o restante destinado ao Estado cubano - e mesmo que essa quantia signifique bastante na sociedade cubana, no Brasil pode implicar problemas de estruturação, em função dos altos custos de vida, principalmente nas grandes cidades. ${ }^{24}$

Do ponto de vista mais geral, um aspecto que não pode passar despercebido para a análise desse trabalho refere-se à flexibilidade da contratação, na forma de bolsa-formação, que deixa explícito o afastamento de "relações empregatícias de qualquer natureza”. Por esse motivo, essas contratações não estão incluídas nas autorizações de trabalho concedidas a estrangeiros pelo Ministério do Trabalho e Emprego. Essa forma de contratação desvincula o Estado brasileiro de todos os encargos de proteção social do trabalho. No fundo, do ponto de vista desse Estado, a solução importadora A é a mais vantajosa economicamente, porque, خे além de ter a pronta entrega de médicos já formados, também reduz custos desembolsados para a prestação desse serviço. ${ }^{25}$

24 Ponderar essas questões não significa, entretanto, assumir o discurso da grande mídia e de posições políticas conservadoras, que não economizaram esforços para consTi trução de uma imagem de "miserabilismo" desses médicos cubanos.

${ }^{25} \mathrm{O}$ contrato inclui, no entanto, a jornada de oito horas diárias, o direito de trinta dias de férias e do afastamento remunerado em caso de doenças. Porém não está incluído o décimo terceiro salário e o FGTS, fundo de garantia. gador, na decisão sobre a necessidade e a possibilidade (financeira) da manutenção desses médicos no país dentro do serviço público de saúde. Desse modo, a continuidade das contratações depende das prioridades do governo. ${ }^{26}$ Quem potencialmente pode pagar o preço desse sistema são os próprios médicos estrangeiros, que não têm segurança sobre a renovação de seu contrato e, em função disso, podem ter de deixar o país. A população carente do Brasil, igualmente, não tem garantia da continuidade da prestação desses serviços.

\section{CONSIDERAÇÕES FINAIS}

O aumento significativo da presença dessa modalidade imigratória no Brasil, durante o período analisado (2007-2014), além de sinalizar diferentes dinâmicas de funcionamento do mercado de trabalho e do aumento do seu grau de internacionalização na atualidade, também demonstra como diferentes categorias profissionais e nacionalidades passam a compor, com um volume significativo, os movimentos migratórios internacionais para o país. Procurou-se trazer elementos para pensar suas principais tendências no contexto brasileiro, que, ao contrário, foi historicamente mais estudado como um país emissor desses fluxos.

$\mathrm{O}$ verdadeiro motor desses movimentos, a começar pelos motivos que impelem essas categorias a emigrarem, normalmente, não está separado de dinâmicas mais gerais do mercado de trabalho - como o desemprego, o rebaixamento de condições laborais e de direitos, a contratação flexível ou mesmo o funcionamento internacionalizado de determinados setores produtivos, financeiros e de serviços. Fatores problemáticos que certamente não cessam de se manifestar no

\footnotetext{
${ }^{26}$ Essa questão ficou evidente no governo Temer, que colocou como uma de suas prioridades máximas mandar de volta os médicos cubanos, a despeito da importância de seu trabalho para a população brasileira mais carente e do amplo reconhecimento pelos brasileiros, usuários do SUS, do trabalho que os médicos cubanos realizam no país. O racismo contra esses médicos agora se manifesta também no âmago do Estado brasileiro. Para o conceito de "racismo de Estado", ver Basso, 2010.
} 
país de imigração, notadamente pela flexibilidade imperante nos contratos dessa força de trabalho internacionalmente recrutada.

Além disso, o nível de escolarização e especialização característico desses fluxos - considerados, na atualidade, como os únicos "desejáveis" pelos Estados - não são suficientes para proteger essas categorias das tendências gerais de precarização do trabalho. O regime do visto temporário (e de curta duração) é um elemento importante para se compreenderem essas tendências, ditadas por uma presença institucionalmente provisória em território nacional, controlada pela flexibilidade exigida pelo mercado e sob a contínua ameaça da indocumentação. Muitos outros elementos mereceriam maior aprofundamento, em particular a manifestação do racismo e da divisão sexual do trabalho nessa modalidade de imigração "selecionada" para entrar pelo circuito documentado do trabalho imigrante, o que, de certa forma, também nos leva a refletir sobre a divisão internacional do trabalho implícita nesses fluxos.

Mas tratamos do caso completamente silenciado da importação dos "forçados do mar" e o dos médicos cubanos - estes, ao contrário, um objeto bastante explorado pela mídia -, trazendo elementos de novidade importantes para se pensar o quadro geral do trabalho imigrante no país. A flexibilidade e a temporalidade importadas são o denominador comum desses trabalhos. Quando não é o próprio Estado que aparece como exportador e (ou) importador dessa força de trabalho, muitas vezes intermediado por agências internacionais, são as empresas transnacionais que conseguem fazer valer sua vontade da importação da flexibilidade internacionalizada da força de trabalho imigrante.

A presença de filipinos no Brasil, para trabalhar nas embarcações de petróleo, é um exemplo claro da funcionalidade de um trabalho que deve ser mantido espacialmente na sua especialidade sobre as águas marítimas, distante da visibilidade dos territórios nacionais que o empregam e onde as plataformas transnacionais podem operar a pleno ritmo, sem pausas ou grandes impedimentos oriundos da organização desses trabalhadores. Essas águas distantes do mar representam o espaço do não direito de um setor produtivo que está em plena expansão no Brasil.

O recrutamento internacional de médicos pelo Programa Mais Médicos demonstra como uma categoria profissional, antes considerada privilegiada e quase "blindada" dos movimentos de precarização do trabalho, hoje também compõe, de forma crescente, os movimentos migratórios em escala internacional. A particularidade do trabalho dos médicos cubanos, embora contenha especificidades e ambivalências que devem ser consideradas, revela igualmente tendências mais gerais, em escala global e nacional, do funcionamento do mercado de trabalho em sua relação com o fenômeno da imigração.

Com a crise econômica que se anuncia grave no Brasil, o recuo do investimento de capital estrangeiro e a aplicação dos ajustes fiscais com cortes significativos nos gastos públicos, certamente haverá uma diminuição dos ingressos desses fluxos no país. Como nos anos 1980 e 1990, o Brasil, agora, se recoloca potencialmente mais como um país emissor desses fluxos que, sem dúvida, serão ainda mais violentos do que nas décadas anteriores. A emigração drenará principalmente seus jovens recém-formados e já diplomados, que estão desempregados, descontentes com as condições laborais ou que não encontram nenhuma perspectiva de trabalho.

No entanto, é necessário lembrar que a demanda estrutural por essa face qualificada-especializada do trabalho imigrante se coloca como uma componente significativa do funcionamento do mercado de trabalho em sua ligação com movimentos migratórios em escala global, portanto, não deixará de existir no país, em particular em setores em expansão, como o do petróleo ou mesmo naqueles impulsionados pela internacionalização.

Recebido para publicação em 21 de abril de 2016 Aceito em 09 de dezembro de 2016 


\section{REFERÊNCIAS}

ALARCÓN, R. Skilled Immigrants and cerebreros: foreignborn engineers and scientists in the high-technology industry of Silicon Valley. In: FONER, N. (Org.). Immigration research for a new century: multidicisplinary perspectives. New York: Russell Sage Foundation, 2000.

ANTUNES, R. (Org.). Riqueza e miséria do trabalho no Brasil II, São Paulo: Boitempo, 2014.

Os sentidos do trabalho: ensaio sobre a afirmação e a negação do trabalho. São Paulo: Boitempo, 2009.

$\therefore$ DRUCK, G. A epidemia da terceirização. In: Riqueza e miséria do trabalho no Brasil III. São Paulo: Boitempo, 2014.

ARAGONÉS, A. M.; SALGADO, U. Mercados de trabajo en la economía del conocimiento y el fenómeno migratorio: el caso de Estados Unidos (1990-2006). In: ARAGONÉS, A. (Org.). Mercados de trabajo y migración Internacional. México: UNAM, Instituto de Investigaciones Económicas, 2011.

ARRAES, J. Home staff anuncia empregadas filipinas e causa indignação. 2015. Disponível em: < http://www. revistaforum.com.br/questaodegenero/2015/04/28/homestaff-anuncia-empregadas-filipinas-e-causa-indignacao/ $\geq$. Acesso em: 28 abr. 2015.

BAENINGER, R. et al. (Org.). Imigração haitiana no Brasil. Jundiaí: Paco, 2016.

Estrangeiros autorizados a trabalhar no Brasil. In: CENTRO DE GESTÃO E ESTUDOS ESTRATÉGICOS. Doutores 2010: estudos da demografia da base técnicocientífica brasileira. Brasília: CGEE, 2010.

BAENINGER, R.; LEONCY, C. Perfil dos estrangeiros no Brasil segundo autorizações de trabalho (Ministério do Trabalho e Emprego) e registros de entradas e saídas da Polícia Federal (Ministério da Justiça). In: COMISSÃO NACIONAL DE POPULAÇÃO E DESENVOLVIMENTO. Migrações Internacionais: contribuições para políticas. Brasília: CNPD, 2001.

BASSO, P. L'ascesa del razzismo nella crisi globale. In:

(Org.). Razzismo di stato: Stati Uniti, Europa, Italia. Milano: FrancoAngeli, 2010.

Sviluppo diseguale, migrazioni, politiche migratorie. $\overline{\mathrm{BAS} S O}$, P.; PEROCCO, F. (Orgs.). Gli immigrati in Europa: diseguaglianze, razzismo, lotte. Milano: Franco Angeli, $\checkmark 2003$

С્ BRAGA, R. A política do precariado: do populismo à :. hegemonia lulista. São Paulo: Boitempo, 2012.

CAMPOS, F. A arte da conquista: o capital internacional no desenvolvimento capitalista brasileiro. 2009. Tese (Doutorado) - Universidade Estadual de Campinas, São in Paulo, 2009.

๗ె COENTRO, L. Políticas públicas e gestão das migrações ¿. internacionais no Brasil: uma reflexão sobre os migrantes के qualificados. 2011. Dissertação (Mestrado) - Fundação શ Getúlio Vargas, São Paulo, 2011.

COMITE NACIONAL PARA OS REFUGIADOS (CONARE)

m Sistema de refúgio brasileiro. Desafios e perspectivas.

$>$ Ministério da Justiça, 2016.

8 CHACON; J. A.; DAVIS, M. No one is illegal: fighting racism and state violence on US-Mexico Border. Chicago: त్ Haymarkert, 2006.

DREHER, S. Neoliberalism and Migration: an inquiry into the politics of globalization. Hamburg: LIT Verlag, 2007.

DRUCK, M. G. Terceirização: (des) fordizando a fábrica: um estudo do complexo petroquímico da Bahia. São 定 Paulo: Boitempo, 1995.
FALQUET, J. Hommes en armes et femmes "de service": Tendances néolibérales dans l'évolution de la division sexuelle et internationale du travail. Cahiers du Genre, Paris, n. 40, 2006, p. 15-37.

FIDDIAN-QUASMIYEH, E. et al. Refugee and forced migration studies. Oxford: Oxford Press, 2014.

GALLINO, L. Il lavoro non è uma merce: contro la flessibilità. Bari: Laterza, 2011.

HARVEY, D. A condição pós-moderna. São Paulo: Ed. Loyola, 1992.

HIRATA, H. A precarização e a divisão internacional e sexual do trabalho. Sociologias, Porto Alegre, ano 11, n. 21, p. 24-41, jan./jun., 2009.

HUWS, U. A construção de um cybertariado? Trabalho virtual num mundo real. In: ANTUNES, R.; BRAGA, R. Infoproletários: degradação real do trabalho virtual. São Paulo: Boitempo, 2009.

KAHANEC, M. Skilled labor flows lessons from the European Union. Bratislav: Central European University, 2013. (Discussion paper, 1301).

KAMMERER, P. Sviluppo del capitale ed emigrazione in Europa: la Germania Federale. Milano: Mazzotta, 1976.

KREIN, J. D. As relações de trabalho na era do neoliberalismo no Brasil. São Paulo: LTR, 2013a.

As transformações no mundo do trabalho e as tendências das relações de trabalho na primeira década do século XXI. NECAT, Florianópolis, v. 2, n. 3, p. 6-65, 2013b.

LIMA, J. (Org.). Outras sociologias do trabalho: flexibilidade, emoções, mobilidade. EDUFSCAR: São Carlos, 2013.

LOPRENO, D. L'immigrazione in Svizzera: XXI. In: GJERGJI, I. (Org.). La nuova emigrazione italiana: cause, mete e figure sociali. Ca' Foscari: Venezia, 2015.

MACKAY, S. (Org.) Refugees, recent migrants and employment: challenging barriers and exploring pathways. New York: Routeledge, 2008.

MARTIN, P. (Org.) Managing Labour Migration in the Twenty-first Century, New Haven: Yale University, 2006.

MASSANET, E.; ANDRÉS, F. Medicos latinoamericanos en Cataluna: processos de integración y desarrollo professional. REMHU - Rev. Interdiscip. Mobil. Hum., Brasília, n. 41, p. 225-240, 2013.

MATTEWAN, J. Os novos nômades globais. São Paulo: Clio, 2012.

MAZZELLA, S. Sociologie des migrations. Paris: Puf, 2014.

MOMO, G. Estrangeiros qualificados: a nova face da imigração no Brasil. 2014. Dissertação (Mestrado) Pontifícia Universidade Católica de São Paulo, São Paulo, 2014.

MOROKVASIC, M. L'(in)visibilité continue. Cahiers du Genre, Paris, n. 51, p. 25-47, 2011.

NEDELCU, M. (Org.). La mobilité internationale des compétences: situations récents, approches nouvelles. L' Harmattan: Paris, 2004.

OLIVER, E. Promoting women? Lessons learned from a study of mobility and fixed-term work in early career researchers. In: HELEN, S.; CURRIE, S.; VELLUTI, S. Gender and Migration in 21st Century Europe. Farnham: Ashgate, 2009.

ORGANIZAÇÃO INTERNACIONAL DO TRABALHO (OIT). Employer's viewpoint on migration, retention and return of health-care workers: an Indian perspective. EUILO: New Delhi, 2014.( Working Paper Series). 
PIZARRO, J. M. Globalizados, pero restringidos: una visión latino-americana del mercado mundial de recursos humanos calificados. CELADE: Santiago, 2005.

PELLEGRINO, A. Tendencias de la migración internacional en América Latina y el de Caribe en la segunda mitad del siglo XX. In: OTEIZA, E. (Org.) Patrones migratorios internacionales en América Latina. Buenos Aires: EUDEBA, 2010

¿Drenaje o éxodo? Reflexiones sobre la migración calificada. In: ENCONTRO ANUAL DA ANPOCS, 25. 2001, Caxambu. Anais..., Caxambu, 16 a 20 out. 2001.

PEROCCO, F. Le discriminazioni razziali nel lavoro: un fenomeno sistematico e multidimensionale. In: FERRERO, M.; PEROCCO, F. (Orgs.). Razzismo al lavoro: il sistema della discriminazione sul lavoro, la cornice giuridica e gli strumenti di tutela. Milano: Franco Angeli, 2011.

PORTES, A. Determinants of Brain Drain. International Migration review, v.10, n. 4, p. 489-508, 2008.

POTTS, Lydia. The World Labour Market: a history of migration. London: Zed Books, 1990.

PRESTON, V.; D'ADDARIO, S. Recent migrantsin the Canadian labour market: exploring the impacts of gender and racialisation. In: MACKAY, S. (Org.) Refugees, recent migrants and employment: challenging barriers and exploring pathways. New York; London: Routeledge, 2008.

ROULLEAU-BERGER, L. Migrer au féminin. Paris: PUF, 2010.

RUIZ, B. Foreign and guest workers: immigration and admissions issues. New Science Publishers: New York, 2011.

SASSEN, S. Brutality and complexity in the global economy. Cambridge: Harvard, 2014.

Dos enclaves en las geografías globales contemporáneas del trabajo. In: ARAGONÉS, Ana M
(Org.). Mercados de trabajo y migración internacional. México: UNAM, Instituto de Investigaciones Económicas, 2011.

"Vers une analyse alternative de la mondialisation: les circuits de survie et leurs acteurs". Cahiers du Genre. Paris, n. 40, p. 67-89, 2006.

The mobility of labor and capital. New York: Cambrige University Press, 1988.

SAYAD, A. A imigração ou os paradoxos da alteridade. São Paulo, Edusp, 1998.

STASIULIS, D. Revisiting the permanent-temporary labour migration dichotomy. In: PELLERIN, H.; GABRIEL, C. Governing international labour migration: challenges and dilemmas. New York: Routledge, 2008.

UNITED NATIONS (UN). Population facts. The number of international migrants worldwide reaches 232 million. United Nations: New York, 2013.

VALOR ECONÔMICO. Especial pré-sal. 23-25 ago. 2014.

VILLEN, P. O trabalho forçadamente indocumentado e institucionalmente silenciado: a imigração dos 'periféricos emergenciais' para o Brasil. Revista da ABET, Paraná, v. 14 p. 186-198, 2016

Imigração na modernização dependente: "braços civilizatórios” e a atual configuração polarizada. 2015 Tese (Doutorado) - Universidade Estadual de Campinas, São Paulo, 2015.

ZANIN, V. I forzati del mare. Roma: Carocci, 2007.

WICKRAMASEKARA, P. Assessment of the impact of migration of health professionals on the labour market and health sector performance in destination countries. International Labour Organization: Geneva, 2014 


\section{THE QUALIFIED-SPECIALIZED FACE OF IMMIGRANT LABOR IN BRAZIL: temporality and flexibility}

\author{
Patrícia Villen
}

The object of this article is the qualified-specialized characteristic of immigrant work related to the legalized circuit of immigration. The references and the different theoretical backgrounds are evaluated highlighting the relevance of the "global market for qualified human resources". The manifestation of these fluxes in Brazil (2007-2014) is analyzed based on the statistics of the Ministry of Health and the Ministry of Labor and Employment about the visa regime, the composition of gender and nationality. A section is dedicated to "global maritimes", and Cuban doctors, because they represent an emblematic case in the new sociohistorical bases of development of the immigration phenomenon in the country. Finally, a balance will be made about the link between these issues and the movements of labor precariousness, in particular those regarding temporality and flexibility.

Keywords: Immigrant labor. Temporality. Flexibility. Global maritime. More Doctors for Brazil Program. Labor Market.

\section{LA FACE QUALIFIÉE-SPECIALISÉE DU TRAVAIL DES IMMIGRANTS AU BRÉSIL: temporalité et flexibilité}

Patrícia Villen

L'objet de cet article est la face qualifiée du travail immigré, lié au circuit d'immigration légalisé. La bibliographie et les différentes aproches théoriques du theme seront examinées, en particulier le prisme du «marché mondial des ressources humaines qualifiées." La manifestation de ces flux au Brésil (2007-2014) est analysée à partir des statistiques du Ministère de la Santé et du Ministère du Travail et de L'emploi sur le régime des visas et la composition de sexe et nationalité. Une section est consacrée au travail des «maritimes globaux» et des médecins cubains, parce qu'ils représentent des cas emblématiques de la nouvelle base socio-historique du développement du phénomène de l'immigration au Brésil. Enfin, la connexion de ces flux avec les mouvements de précarisation du travail sera consideré, en particulier en ce qui concerne la temporalité et la flexibilité.

MotS-CLÉs: travail immigré, temporalité, flexibilité, maritimes globaux, Programe Mais Médicos. Departamento de Ciências Sociais da Universidade Federal de Uberlândia e Pesquisadora de Pós-Doutorado na Universidade Estadual de Campinas. Integra o Núcleo de Pesquisa Estudos sobre o mundo do trabalho e suas metamorfoses (Instituto de Filosofia e Ciências Humanas da Unicamp), desenvolvendo pesquisas na área de migrações internacionais, trabalho e racismo. Suas mais recentes publicações são: O trabalho forçadamente indocumentado e institucionalmente silenciado: a imigração dos "periféricos emergenciais" para o Brasil. Revista da ABET, 2016; Imigração e racismo na modernização dependente do mercado de trabalho. Lutas Sociais, 2015; O estigma da ameaça ao emprego pelos "periféricos na periferia": crise e imigração no Brasil. Rua, 2015; Periféricos na periferia. In: BAENINGER, R. et al. (Orgs.). Imigração haitiana no Brasil. Jundiaí: Paco, 2016; A nova configuração da imigração no Brasil sob a óptica do trabalho. In: ANTUNES, R. (Org.) Riqueza e Miséria do Trabalho no Brasil III. São Paulo: Boitempo, 2014. 